\title{
Spectrum of radiological presentations of Intracranial Glioma among the Indian population
}

\author{
Shilpi Muchhoria', Sourabh Dixit' ${ }^{2}$, Manpreet Singh Banga ${ }^{3}$, Partha Ghosh ${ }^{4}$, \\ Abhishek Nadkarni ${ }^{5}$, Nakul Pahwa ${ }^{5}$ \\ ${ }^{1}$ Consultant and Head, Department of Radiodiagnosis, National Hospital Bhopal, Madhya Pradesh, India, ${ }^{2}$ Assistant \\ Professor, Department of Neurosurgery, Bhopal Memorial Hospital and Research Centre, Bhopal, Madhya Pradesh, \\ India, ${ }^{3}$ Assistant Professor, Department of Neurosurgery, Vydehi Medical College, Bangalore, Karnataka, India, \\ ${ }^{4}$ Consultant Neurosurgeon, Institute of Neurosciences Kolkata, West Bengal, India, ${ }^{5}$ Post Doctoral Fellow Pediatric \\ Neurosurgery Park Clinic, Kolkata, West Bengal, India, ${ }^{6}$ Post Doctoral Trainee, Department of Neurosurgery, Nil Ratan \\ Sircar Medical College, Kolkata, West Bengal, India
}

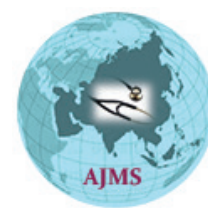

A B S T R A C T

Background: Gliomas comprises the group of most common primary tumour of central nervous system. The current study was undertaken to evaluate the various usual and unusual radiological presentations among the patients of glioma among the Indian population.Aims and Objective: The aim of the current study was to observe the various radiological presentations of glioma occurring among the subjects. It was also intended to correlate the radiological and histopathological grading in glioma among subjects. Materials and Methods: The current study was a prospective observational study carried out among seventy-five patients admitted in a tertiary care hospital in Eastern India with provisional diagnosis of supratentorial glioma and operative biopsy confirmed to be Glioma. Results: The most common grade of tumour encountered was grade IV tumour. Of the clinical features, $70.66 \%$ patients had hypodense lesion, $25.33 \%$ patients had iso dense and hypodense (mixed density) lesion and 3 patients had hyperdense lesion on CT Brain. On MRI in T1 Weighted images, $81.33 \%$ patients had hypointense lesion lesion on MRI T1 image. On T2 Weighted Images, $76 \%$ patients had hyperintense lesion., $77.33 \%$ demonstrated heterogenous enhancement. Ring enhancement was seen in 9 cases Minimal to no enhancement was seen in 8 cases. MRS showed maximum cases had Choline peak with altered Choline: creatinine ratio and decreased NAA peaks. Conclusion: Good imaging interpretations is crucial for planning of surgical excision and adjuvant radiotherapy. This review has been put to solve the basic problem in interpreting the Ct Scan and MRI of Glioma.

Key words: Glioma; MRI; MRS; Contrast Enhancing; ICSOL

\section{INTRODUCTION}

Gliomas comprises the group of most common primary tumour of central nervous system which accounts for $30 \%$ of brain and central nervous system tumour and overall $80 \%$ of all malignant brain tumours. ${ }^{1}$ They are glial cells derived neoplasm and may be broadly divided into supratentorial and infratentorial based on location of origin or according to WHO grades as low grade glioma (grade I \& II) and high grade glioma (grade III \& IV)..$^{2-8}$

Neuroradiological evaluation is backbone of diagnosis of Glioma. Neuroimaging is not diagnostic but may suggest a particular pathologic subtype of glioma by virtue of the tumour's location and imaging characteristics. ${ }^{9,10}$ Proper interpretation of images is a crucial step in proper diagnosis and planning of treatment of gliomas. CT Scan and

Address for Correspondence:

Dr. Sourabh Dixit, Assistant Professor, Department of Neurosurgery, Bhopal Memorial Hospital and Research Centre, Bhopal, Madhya

Pradesh, India. Mobile Number: +91-9163866571. E-mail: sourabhdixit1011@gmail.com 
Magnetic resonance imaging (MRI) are two most widely accepted imaging modalities for gliomas. The current study was undertaken to evaluate the various usual and unusual radiological presentations in the patients of glioma among the Indian population.

\section{Aims and objectives}

The current study was aimed to observe the various radiological presentations of glioma occurring among the subjects. It was also intended to correlate the radiological and histopathological grading in glioma among subjects.

\section{MATERIALS AND METHODS}

The current study was conducted in the department of Neurosurgery, Nilratan Sircar Medical College \& Hospital, Kolkata for a period of two years from October 2014 till September 2016. The total number of subjects included in the study was seventy five with all patients admitted with Supratentorial glioma in Neurosurgery ward for operative treatment. The study was a prospective observational study and the patient's selection for the study included both genders of various age group. The inclusion criteria of the subjects were all patients with supratentorial gliomas admitted for surgery. The exclusion criteria were those patients with infratentorial gliomas and non operated cases of Supratentorial gliomas.

The parameters included for the study among each patients were, occurrence, location, number, radiological presentations and histopathological findings with tumor grades.

\section{RESULTS}

The current study included 75 patients of glioma. The study observed the demographic profiles, imaging features and histopathology and tumour grading of the selected patients.

Table 1 shows the age distribution of the study subjects.

The most common age group (Table 1) encountered was 41 to 50 years which comprised of 17 patients $(22.66 \%)$, followed by 16 patients $(21.33 \%)$ in the age group of $51-60$ years. Thirteen patients $(17.33 \%)$ were in age group of $31-40$ years and 11 patients $(14.66 \%)$ were in age group of $21-30$ years. Subsequently 7 patients in 11-20 years, 5 in 71-80 years, 3 in 61-70 years and 3 in 1-10 years of age. The mean age of the patients was 41.67 years. For low grade glioma was 33.22 years and mean age for high grade gliomas was 46 years (data not shown).

\section{Grade}

The most common grade of tumour encountered (Table 2) was grade IV tumour comprising of 39 patients (52\%), followed by 21 patients $(28 \%$ ) of Grade II, 8 patients $(10.66 \%)$ of Grade III and 7 patients (09.33\%) in Grade I tumours. The maximum number of high grade gliomas (grade III \&IV) were $>40$ years of age and $41-50$ years age group having maximum cases.

Of those 75 patients (Table 2), 40 patients $(53.33 \%$ ) had one lobe involvement, 29 patients $(38.66 \%)$ had more than one lobe involvement. Three patients had periventricular region tumour and 3 patients showed corpus callosum involvement.

All patients underwent CT scan of brain during evaluation. The results are presented in Table 3.

Out of 75 patients, (Table 3 and Figures $1 \mathrm{a}-\mathrm{c}$ ) 53 patients had hypodense lesion (70.66\%),19 patients had iso dense

\begin{tabular}{lcc} 
Table 1: Age wise distribution of patients & \\
\hline & Males & Females \\
\hline 0-upto1 year & 0 & 0 \\
1 years to 10 years & 3 & 0 \\
11 years to 20 years & 1 & 6 \\
21 years to 30 years & 4 & 7 \\
31 years to 40 years & 9 & 4 \\
41 years to 50 years & 14 & 3 \\
51 years to 60 years & 14 & 2 \\
61 years to 70 years & 1 & 2 \\
71 years to 80 years & 2 & 3 \\
$>80$ years & 0 & 0 \\
\hline
\end{tabular}

\begin{tabular}{|c|c|c|c|c|}
\hline $\begin{array}{l}\text { Location wise } \\
\text { distribution }\end{array}$ & $\begin{array}{c}\text { Grade } \\
\text { I }\end{array}$ & $\begin{array}{c}\text { Grade } \\
\text { II }\end{array}$ & $\begin{array}{c}\text { Grade } \\
\text { III }\end{array}$ & $\begin{array}{c}\text { Grade } \\
\text { IV }\end{array}$ \\
\hline Right frontal & & 2 & & 3 \\
\hline Left frontal & & 2 & 2 & 6 \\
\hline Right parietal & & & 1 & 2 \\
\hline Left parietal & & & & 1 \\
\hline Right Temporal & & 2 & & 2 \\
\hline Left temporal & 1 & & & 4 \\
\hline Right occipital & 2 & 2 & 1 & 3 \\
\hline Left occipital & & & & 1 \\
\hline $\begin{array}{l}\text { Basal ganglion and } \\
\text { thalamus }\end{array}$ & 1 & 1 & & 1 \\
\hline $\begin{array}{l}\text { More than I lobe } \\
\text { involved }\end{array}$ & 3 & 10 & 2 & 14 \\
\hline Corpus Callosum & & 1 & & 2 \\
\hline Periventricular & & 1 & 2 & \\
\hline Total Number Of cases & 7 & 21 & 8 & 39 \\
\hline
\end{tabular}

\begin{tabular}{lc} 
Table 3: CT scan of Brain during evaluation \\
\hline Appearance on CT & No. of Patients \\
\hline Hypodense & 53 \\
Mixed (Hypo+lso) & 19 \\
Hyperdense & 3 \\
\hline
\end{tabular}


and hypodense (mixed density) lesion(25.33\%) and rest 3 patients had hyperdense lesion on CT Brain.

Out of 75 patients (Table 4 and Figures 2 a-c) on T1 weighted images, 61 patients $(81.33 \%)$ showed hypointense lesion and 12 patients had iso to hypointense lesion (16\%). Two patients had hyperintense lesion on MRI T1 image. On T2 weighted images, 57 patients $(76 \%)$ had hyperintense lesion, 18 patients $(24 \%)$ had hyper to isointense i.e mixed intensity lesion.

\section{Findings of MIRI T1 and contrast image}

All 75 patients had IV contrast study (Figure 3 a-f) and maximum patients $(77.33 \%)$ demonstrated heterogenous enhancement comprising 4 patients with grade I tumour, 15 patients with grade II tumour, 8 patients with grade III tumour and 31 patients with grade IV tumour. Ring

\begin{tabular}{|c|c|c|c|c|}
\hline Intensity on MRI T1w & $\begin{array}{c}\text { Grade } \\
\text { I }\end{array}$ & $\begin{array}{c}\text { Grade } \\
\text { II }\end{array}$ & $\begin{array}{c}\text { Grade } \\
\text { III }\end{array}$ & $\begin{array}{c}\text { Grade } \\
\text { IV }\end{array}$ \\
\hline Isointense & 0 & 0 & 0 & 0 \\
\hline Hypointense & 2 & 19 & 8 & 32 \\
\hline Mixed (Iso+Hypo) & 5 & 0 & 0 & 7 \\
\hline $\begin{array}{l}\text { Hyperintense } \\
\text { Intensity on MRI T2w }\end{array}$ & 0 & 2 & 0 & 0 \\
\hline Isointense & 0 & 0 & 0 & 0 \\
\hline Hypointense & 0 & 0 & 0 & 0 \\
\hline Hyperintense & 7 & 18 & 8 & 24 \\
\hline Mixed (Hyper+lso) & 0 & 3 & 0 & 15 \\
\hline \multicolumn{5}{|l|}{ MRI T1w+Contrast } \\
\hline Homogenous & 0 & 0 & 0 & 0 \\
\hline Heterogenous & 4 & 15 & 8 & 31 \\
\hline Ring Enhancement & 1 & 0 & 0 & 8 \\
\hline Minimal-no enhancement & 2 & 6 & 0 & 0 \\
\hline GRE & 0 & 15 & 3 & 34 \\
\hline DWI & 0 & 6 & 5 & 30 \\
\hline FLAIR & 0 & 8 & 6 & 39 \\
\hline \multicolumn{5}{|l|}{ MRS Total 50 cases } \\
\hline $\begin{array}{l}\text { Elevated Choline } \\
\text { peak/Altered Choline: } \\
\text { creatinine ratio }\end{array}$ & 0 & 16 & 5 & 29 \\
\hline Decreased NAA peak & 0 & 16 & 5 & 29 \\
\hline Lactate peak & 0 & 8 & 0 & 16 \\
\hline Inositol peak & 0 & 5 & 0 & 4 \\
\hline
\end{tabular}

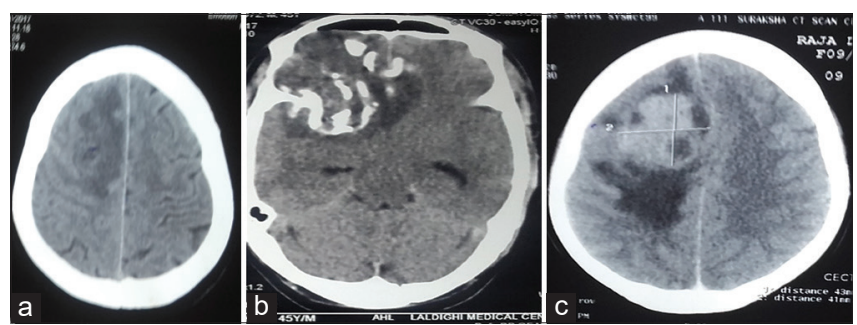

Figure 1: (a) Hypodense lesion in right premotor area with surrounding hypodense perilesional edema. (b) Mixed density lesion in right frontal region with hyperdensity within hypodense lesion suggestive of intratumoural calcification. (c) CT Scan showing a hyperdense lesion in right frontal region with surrounding hypodense perilesional edema enhancement was seen in 9 cases comprising 1 patient with grade I tumour and 8 patients with grade IV tumour. Minimal to no enhancement was seen in 8 cases comprising 2 patient with grade I tumour, 6 patients with grade II tumour.

Gradient-echo sequence (GRE) study (Figure 4 a-c) showed blooming in 52 cases $(69.33 \%)$ comprising 15 patients with grade II tumour, 3 patients with grade III tumour and 34 patients with grade IV tumour.

Diffusion weighted imaging (DWI) study (Figure 5) showed Restricted diffusion in 41 cases $(54.66 \%)$ comprising 6 patients with grade II tumour, 5 patients with grade III tumour and 30 patients with grade IV tumour.

\section{Fluid attenuation and recovery (FLAIR)}

FLAIR hyperintensities surrounding the lesion (Figure $6 \mathrm{a}, \mathrm{b}$ ) were demonstrated in 53 patients $(70.66 \%)$ comprising 8 patients with grade II tumour, 6 patients with grade III tumour, 39 patients with grade IV tumour.

\section{Magnetic resonance spectroscopy (MRS)}

Fifty patients had Magnetic Resonance Spectroscopy (MRS, Figure 7 a-e) study. 16 patients with grade II tumour, 5 patients with grade III tumour, 29 patients with grade IV tumour had Choline peak with altered Choline: creatinine ratio and decreased NAA peaks. Eight patients with grade II tumour, 16 patients with grade IV tumour had lactate peaks and 5 patients with grade II tumour and 4 patients with grade IV tumour had inositol peaks.

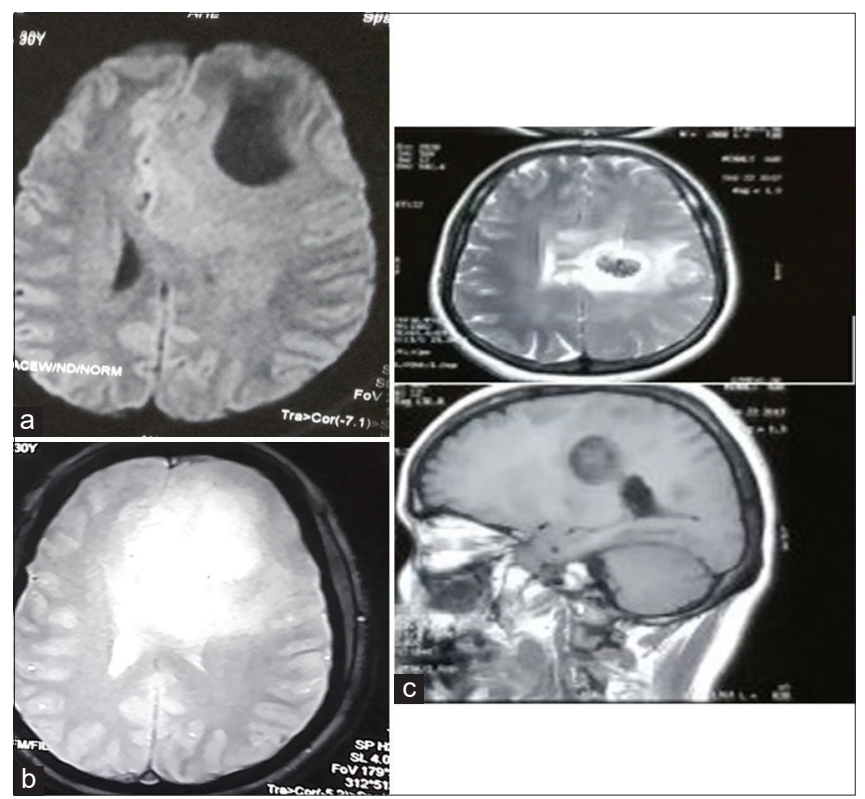

Figure 2: (a-b) Showing a hypointense lesion with mass effect in left frontal region on $\mathrm{T} 1$ weighted images and same lesion appearing hyperintense on T2 weighted images. (c) Showing a showing a leasion in left frontal lobe which is predominantly hypointense on T 2 weighted images and hypointense on T1 weighted images. 




Figure 3: Showing various patterns of contrast enhancement by glioma. (a) showing a homogenous contrast enhancement with perilesional edema. (b) showing ring shaped enhancement. (c) showing heterogenous enhancement with mass effect. (d) showing a post operated case with residual enhancing lesion at the local site in right hemisphere and faint ring like enhancing lesion in left hemisphere suggestive of recurrence of glioma. (e) showing enhancing lesion with adjacent Dural enhancement showing faint Dural tail. (f) showing spread of glioma across the corpus callosum

\section{DISCUSSION}

Imaging (CT scan findings)

CT scan is often the first modality of imaging. It is fast, cheap and more easily accessible and its significant use in emergency settings. But it is less sensitive in delineating margins and extent of lesions is poorly demarcated and at times CT scan may be normal. In the current study $70.66 \%$ patients had hypodense lesion, $25.33 \%$ patients had iso dense and hypodense (mixed density) lesion and rest 3 patients had hyperdense lesion on CT Brain. Focal hyper densities on $\mathrm{Ct}$ scan may be due to calcium or blood. Intra tumour haemorrhage is more common among high grade glioma (grade IV and II) and calcification is relatively less commonly seen among the high grade glioma but more commonly seen in low grade glioma (grade I and II). ${ }^{11}$

Similar results were obtained by Butler et a ${ }^{12}$ on pre contrast CT Scan. Among 60 patients, $86.66 \%$ patients had hypodense lesion and 5\% patients had iso to hypodense lesion. $8.27 \%$ had hyperdense lesion on CT scan Images. Calcification is seen in about $20 \%$ of Astrocytoma and haemorrhage is more common if there is an oligodendroglial component.

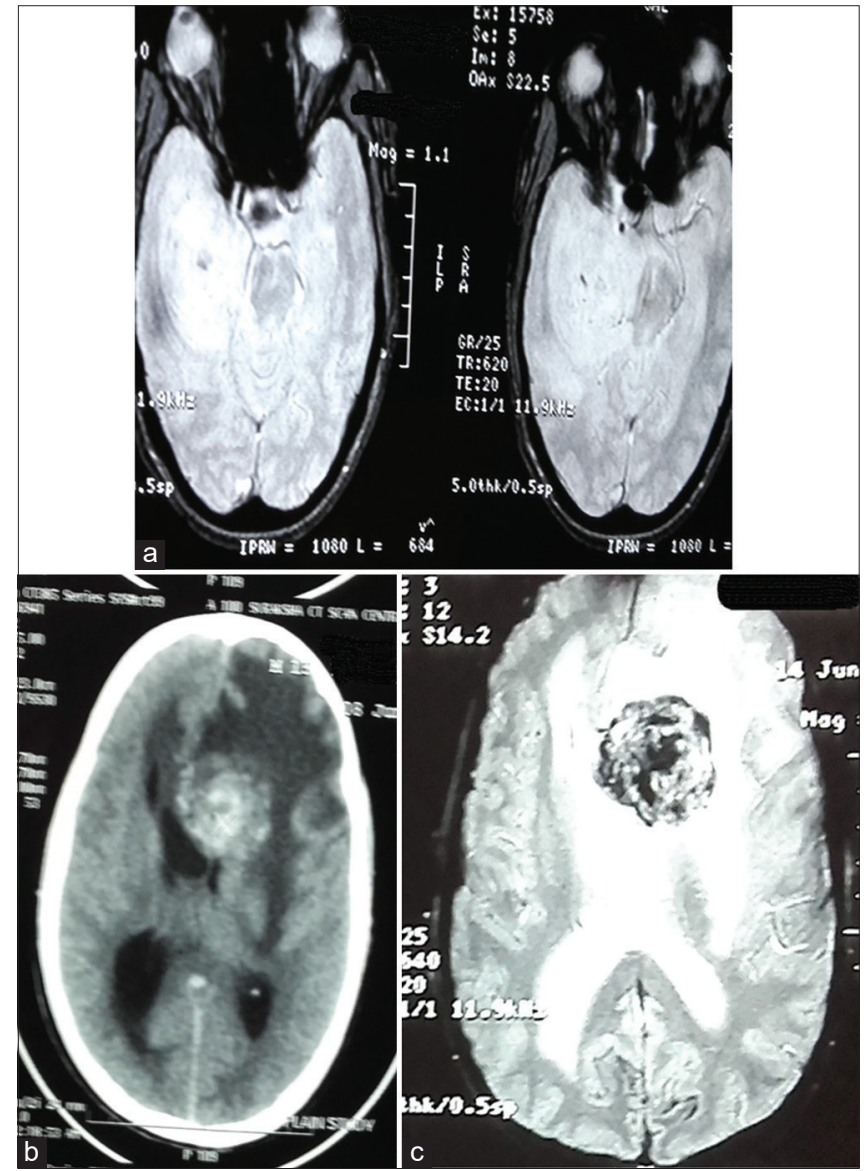

Figure 4: (a) Showing GRE images of right temporal glioma showing intra tumoral blooming. (b-c) showing CT scan image with hyper density within the lesion in left frontal region and corresponding GRE image showing blooming within the lesion

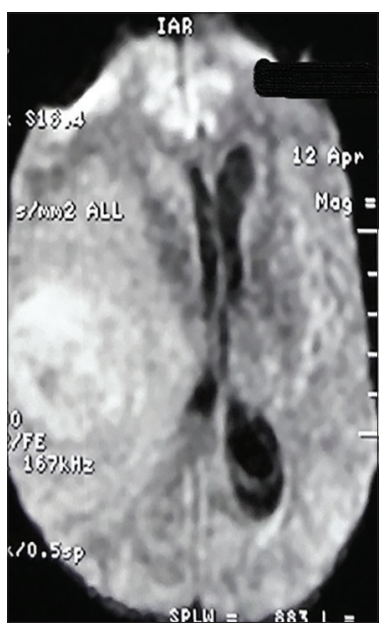

Figure 5: Showing a high grade glioma in right temporal region showing diffusion restriction

\section{MRI}

Out of 75 patients on T1 Weighted Images, 61 patients $(81.33 \%)$ had hypointense lesion and 12 patients had iso to hypointense lesion (16\%). 2 patients had hyperintense lesion on MRI T1 Image. On T2 Weighted Images, 


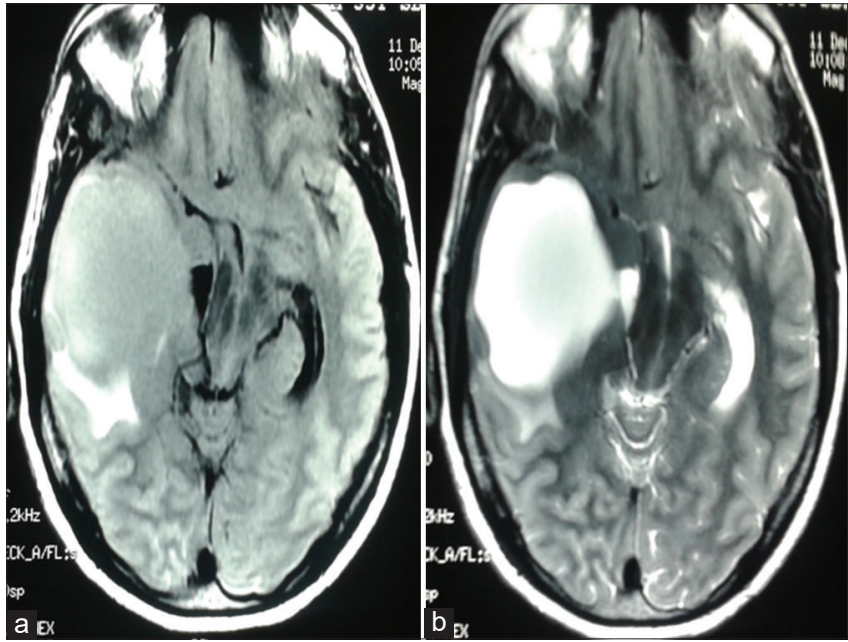

Figure 6: (a-b) Showing a FLAIR image and corresponding T2 image showing a glioma in right temporal region which is hyperintense on T2 weighted images and hyper intensity not suppressed on FLAIR images

57 patients (76\%) had hyperintense lesion, 18 patients (24\%) had hyper to isointense i.e mixed intensity lesion.

Researchers have reported cases with T1 hyperintensity on imaging and ascribed it to intratumoral bleedings as in cases of angiocentric glioma. ${ }^{13}$

\section{MRI T1 and contrast image}

All 75 patients had IV contrast study and maximum patients $(77.33 \%)$ demonstrated heterogenous enhancement comprising 4 patients with grade I tumour, 15 patients with grade II tumour, 8 patients with grade III tumour, 31 patients with grade IV tumour. Ring enhancement was seen in 9 cases comprising 1 patient with grade I tumour and 8 patients with grade IV tumour. Minimal to no enhancement was seen in 8 cases comprising 2 patients with grade I tumour, 6 patients with grade II tumour.

Maria. J Borja et al ${ }^{14}$ in their study showed that Low-grade gliomas (Diffuse Infiltrative variety) tend to be located in the cortical and subcortical regions of the temporal and frontal lobes. In MRI scans, they appear hyperintense on T2-weighted images, PD and (FLAIR)fluid attenuated inversion recovery images and mildly hypointense on T1-weighted images ill-defined margins. They usually do not take up contrast medium and are not surrounded by perifocal brain oedema. ${ }^{1-15}$ In contrast to this circumscribed glioma like Pilocytic astrocytoma are sharply marginated and show contrast enhancement as globular mass or thick irregular rings and may be associated with cystic changes. Anaplastic Astrocytoma It is marked by the heterogeneity in areas of low density, iso density and even areas of hyper density on non-contrast CT. Similarly, on MR, variations in intensities in the various imaging sequences are noted. The


Figure 7: (a) Showing a heterogeneously enhancing lesion in left frontal region. (b) showing suppressed NAA peak and elevated Choline peak in the lesion. (c) showing suppressed NAA peak and elevated Choline peak and raised choline: creatinine ratio in the margin of ring enhancing lesion. (d) showing spectroscopy from normal brain parenchyma surrounding the lesion showing elevation in NAA peak and reduced Choline peak. (e) showing NAA peak and Choline peak,creatinine peak, Lipid lactate peak and small MI peak within the lesions

border of the lesion may be prominent than in a low grade tumour. The enhancement on CT or MR takes the form of a thick ring or a nodule. There is more oedema than in a low-grade tumour.

\section{Does enhancement predicts malignant nature?}

Enhancement alone does not predict malignant nature. ${ }^{14}$ Scott JN et al ${ }^{16}$ have found that enhancing tumours may have a benign histology (e.g. desmoplastic infantile astrocytoma) and one-third of non-enhancing tumours may be malignant. 
Chamberlain $\mathrm{MC}$ et $\mathrm{a}^{17}$ reported that absence of contrast enhancement on CT is observed in 54\% of anaplastic astrocytoma and in 4\%of glioblastomas.

Toh and Castillo ${ }^{18}$ have also mentioned studies with cases of GBM without enhancement in MR.

Kelly PJ et $\mathrm{al}^{19}$ in their study found that Glioblastoma Multiforme may have variegated appearance and usually associated mass effect. The secondary glioblastoma has characteristics of the low-grade tumour from which it developed and associated imaging features of neovascularity, haemorrhage or necrosis. The primary tumours on the other hand show a thick, shaggy and serpiginous pattern of enhancement all over the tumour.

\section{Significances of blooming in GRE}

Gradient-echo sequence (GRE) study showed blooming in 52 cases $(69.33 \%)$ comprising 15 patients with grade II tumour, 3 patients with grade III tumour and 34 patients with grade IV tumour. Schneider t et al [34] also had similar blooming on T2-weighted gradient-echo sequence due to blood and calcifications. Whereas calcification is more common in oligodendrocytic lineage, Intra tumoral haemorrhage is more frequent in high grade glioma like glioblastoma multiforme.

\section{Significance of diffusion restriction}

Maria J Borja et $\mathrm{al}^{14}$ showed the use of DWI and ADC values for differentiating low- from high-grade glial tumours has not been proven given the considerable overlap of ADC values. These values, however, may be helpful in differentiating post radiation changes from glioma recurrence, with lower ADC values being found in recurrent tumours because of increased cellularity.

\section{MRS}

In current study I patient with grade I tumour, 8 patients with grade II tumour, 1 patients with grade III tumour, 11 patients with grade IV tumour had Choline peak with altered Choline: creatinine ratio and decreased NAA peaks. 6 patients comprising 1 patient with grade I tumour, 3 patients with grade II tumour, 2 patients with grade IV tumour had lactate peaks and 2 patients with grade II tumour had inositol peaks.

Borja et $\mathrm{al}^{14}$ found that MRS may be able to distinguish between low- and high-grade gliomas with an accuracy of $78-96 \%$. The measurement of choline can aid in grading gliomas because high-grade gliomas tend to show higher choline-to-creatine and choline-to-NAA ratios than low grade gliomas. Nevertheless, high levels of choline have also been reported in some low-grade tumours, so falsepositive scan occur. Generally, in highly metabolic tumours, including glioblastoma, the levels of NAA and $\mathrm{Cr}$ are decreased, and the rapid growth results in elevated Cho and Lac levels. Thus, in comparison with normal tissues, glioblastoma demonstrates an increase in $\mathrm{Cho} / \mathrm{Cr}$ and Cho/NAA peak ratios, an increased Lac/Cho peak ratio, and a decreased NAA/Cr ratio.

Schneider $\mathrm{T}^{20}$ showed MRS can be used to differentiation of tumours from non-neoplastic brain lesions and also providing an indication of the degree of malignancy of the tumour.

Castillo M, Smith JK, Kwock L ${ }^{21}$ showed that a myoinositol peak can be present in case of low grade glioma were as it is normal in case of high grade glioma.

\section{CONCLUSION}

A proper understanding of imaging sequences and corelating of one sequence with other can provide a valuable information in overall diagnosis of Glioma and differentiating it from other pathologies. Good imaging interpretations is crucial for planning of surgical excision and adjuvant radiotherapy. This review has been put to solve the basic problem in interpreting the CT Scan and MRI of Glioma.

\section{REFERENCES}

1. Goodenberger $\mathrm{ML}$ and Jenkins RB. Genetics of adult glioma. Cancer Genet 2012; 205: 613-621.

https://doi.org/10.1016/j.cancergen.2012.10.009

2. Legler JM, Lynn A, Gloeckler Ries, Malcolm A. Smith, Joan L. Warren, Ellen F. Heineman, et al. Brain and other central nervous system cancers: recent trends in incidence and mortality. J Natl Cancer Inst 1999; 91:1382-1390.

https://doi.org/10.1093/jnci/91.16.1382

3. Janny P, Cure H, Mohr M, Heldt N, Kwiatkowski F, Lemaire JJ, et al. Low grade supratentorial astrocytomas. Management and prognostic factors. Cancer 1994; 73:1937-1945.

4. Kitahara M. Clinical analysis of glioma: low-grade astrocytoma. In: Suzuki J, eds. Treatment of glioma. Berlin: Heidelberg: New York: Tokyo: Springer 1988:173-186.

https://doi.org/10.1007/978-4-431-68453-4_10

5. Kleihues P, Burger PC and Scheithauer BW. The new WHO classification of brain tumours. Brain Pathology 1993; 3:255-268.

https://doi.org/10.1111/j.1750-3639.1993.tb00752.x

6. Kleihues P. Pathology and genetics of tumours of the nervous system. In: Kleihues P, Cavenee WK (Eds). World Health Organization Classifi cation of Tumours, $3^{\text {rd }}$ edition.Lyon, France: IARC Press; 2000

7. Kleihues P, Louis DN, Scheithauer BW, Rorke LB, Reifenberger G, Burger PC, et al. The WHO classification of tumours of the nervous system. J Neuropathol Exp Neurol 2002;61:215-225. https://doi.org/10.1093/jnen/61.3.215

8. Bailey $P$ and Cushing $H$. A classifi cation of tumours of the 
glioma group. Philadelphia: Lippencott; 1926. pp. 54-56.

9. Lee YY, Van Tassel P, Bruner JM, Moser RP and Share JC. Juvenile pilocytic astrocytomas: CT and MR characteristics. Am J Roentgenol 1989; 152:12631270.

https://doi.org/10.2214/ajr.152.6.1263

10. Dirks PB, Jay V, Becker LE, Drake JM, Humphreys RP, Hoffman HJ, et al. Development of anaplastic changes in low grade astrocytomas in childhood. Neurosurgery 1994;34:68-78. https://doi.org/10.1227/00006123-199401000-00010

11. Radiologic-Pathologic Correlation: Intracranial Astrocytoma Mauricio Castillo, James H. Scat/iff, Thomas W. Bouldin, and Kinuko Suzuki From the Departments of Radiology, Section of Neuroradiology (MC, JHS), and Pathology, Section of Neuropathology (TWB, KS), University of North Carolina School of Medicine, Chapel Hill, NC

12. Butler AR, Passalaqua AM, Berenstein A and Kricheff II. Contrast enhanced CT scan and radionuclide brain scan in supratentorial gliomas American Journal of Roentgenology 1979; 132(4): 607-611. https://doi.org/10.2214/ajr.132.4.607

13. Aguilar HN, Hung RW, Mehta $V$ and Kotylak T. Imaging characteristics of an unusual, high-grade angiocentric glioma: a case report and review of the literature. J Radiol Case Rep 2012; $6(10): 1-10$

https://doi.org/10.3941/jrcr.v6i10.1134

14. Borja MJ, Plaza MJ, Altman N, Saigal G. Conventional and Advanced MRI Features of Pediatric Intracranial Tumours: Supratentorial Tumours. AJR 2013; 200:W483-W5030361803X/13/2005-W483.
https://doi.org/10.2214/AJR.12.9724

15. Yeole BB. Trends in the brain cancer incidence in India. Asian Pac J Cancer Prev 2008;9:267-270.

16. Scott JN, Brasher PM, Sevick RJ, Rewcastle NB and Forsyth PA. How often are nonenhancing supratentorial gliomas malignant? A population study. Neurology 2002;59(6):947-949. https://doi.org/10.1212/WNL.59.6.947

17. Chamberlain MC, Murovic JA and Levin VA. Absence of contrast enhancement of CT scans of patients with supratentorial malignant gliomas. Neurology 1988; 38(9):1371-1374. https://doi.org/10.1212/WNL.38.9.1371

18. Toh $\mathrm{CH}$ and Castillo M. Early-Stage Glioblastomas: MR Imaging-Based Classification and Imaging Evidence of Progressive Growth. American Journal of Neuroradiology 2017; 38 (2) 288-293.

https://doi.org/10.3174/ajnr.A5015

19. Kelly PJ, Daumas-Duport C, Kispert DB, Kall BA, Scheithauer BW, Illig JJ, et al. Imaging based stereotactic serial biopsies in untreated intracranial glial neoplasms. J Neurosurg 1987;66(6):865-874 https://doi.org/10.3171/jns.1987.66.6.0865

20. Schneider T, Mawrin C, Scherlach C, Skalej M and Firsching R. Gliomas in adults. Dtsch Arztebl Int 2010; 107(45): 799-808. https://doi.org/10.3238/arztebl.2010.0799

21. Castillo M, Smith JK and Kwock $L$ correlation of myo-inositol levels and grading of cerebral astrocytomas. Am J Neuroradiol 2000; 21(9):1645-1649.

Authors Contribution:

SM, AN, NP- Drafting of Manuscript, Collection of Data, Proof reading, Operating Assistant; SD, MSB, PG, AN- Design of study, main operating surgeons, selection of cases, drafting of script; PG- Concept of study, revision of manuscript, operating surgeon.

Work attributed to:

Department of Neurosurgery, Nilratan Sircar Medical College \& Hospital, Kolkata.

Orcid ID:

Dr. Shilpi Muchhoria - (D https://orcid.org/0000-0001-5000-5772

Dr. Sourabh Dixit - (iD https://orcid.org/0000-0003-1085-7000

Dr. Manpreet Singh Banga - (1) https://orcid.org/0000-0001-9102-9041

Dr. Partha Ghosh - (1) https://orcid.org/0000-0002-8510-77764

Dr. Abhishek Nadkarni - (D) https://orcid.org/0000-0003-2842-4756

Dr. Nakul Pahwa - (1) https://orcid.org/0000-0003-2992-9211

Source of Support: None, Conflicts of Interest: None. 